\title{
Immediate rehabilitation with feeding appliance of a three day old neonate with cleft lip and palate- $A$ case report
}

\author{
Deepika Kapoor ${ }^{1}$, Deepanshu Garg ${ }^{2}$ \\ ${ }^{1}$ Department of Pediatric and Preventive Dentistry, ${ }^{2}$ Department of Oral Medicine and Radiology, College of
} Medical Sciences, Bharatpur, Nepal

\section{Correspondence}

Dr. Deepika Kapoor,

Department of Pediatric and

Preventive Dentistry, College of

Medical Sciences, Bharatpur,

Nepal

Email:dpkaansh@gmail.com

DOI: http://dx.doi.org/10.3126/ jemsn.v13i2.17122

Article received: $3^{\text {rd }}$ Aprril 2016 Article accepted: $12^{\text {th }}$ June 2017

\section{ABSTRACT}

Orofacial clefts (OFC) are one of the most common congenital problems seen with a very high incidence. It imparts a negative effect on the overall health of the child by hindering in his feeding practices, normal facial growth, development of dentition and hence speech. Infants born with orofacial clefts have oronasal communication which creates a problem with the creation of negative pressure inside the oral cavity required for suckling.

The treatment for such patients is with the multidisciplinary approach but the preliminary concern for the neonate is to help with the feeding for which a feeding appliance is given. This case report presents a case of a 3 -day old infant to whom a feeding appliance was given to aid in suckling.

Key words: Cleft lip and palate; feeding obturator; infant; suckling

Citation: Kapoor D, Gard, D. Immediate rehabilitation with feeding appliance of a three day old neonate with cleft lip and palate- A case report. JCMS Nepal. 2017;13(2):293-5.

\begin{abstract}
INTRODUCTION
Human face has infinite variations of its constitution and expression. An unpleasant dental appearance can stigmatize a person, hinder professional achievement, encourage negative stereotypes, and have a negative effect on selfesteem. An unattractive physical appearance might evoke an unfavourable social response. Orofacial

inside the oral cavity required for suckling. ${ }^{4,5}$

The treatment for such patients is with the multidisciplinary approach but the preliminary concern for the neonate is to help with the feeding for which a feeding appliance is given. ${ }^{6}$ This case report presents a case of a three days old infant to whom a feeding appliance was given to aid in suckling.
\end{abstract} clefts (OFC) are one of the most common congenital problems seen with a very high incidence. ${ }^{1}$ The prevalence of OFCs varies from $1 / 500$ to $1 / 2500$ births depending on the geographic origin, racial and ethnic backgrounds, and socioeconomic status. Asians have the highest risk (14:10,000 births) followed by whites $(10: 10,000$ births) and African Americans (4 : 10,000 births) $)^{2}$ It imparts a negative effect on the overall health of the child by hindering in his feeding practices, normal facial growth, development of dentition and hence speech. ${ }^{3}$ At birth the neonate's survival depends on instinctive sucking when lips and tongue are stimulated. To obtain milk from the mother's breast, the infant stimulates the smooth muscle in the breast to contract and express milk onto the tongue; this is suckling. Infants born with orofacial clefts have oronasal communication which creates a problem with the creation of negative pressure

\section{CASE REPORT}

This report presents a case of a boy born in the College of Medical Sciences, Bharatpur,Nepal with a cleft lip and palate. The infant was born at fullterm, with unilateral cleft lip of right side[Figure 1] and soft palate defect [Figure 2], weighing $3.5 \mathrm{~kg}$, and had no family history of clefting or any other congenital defect. The department of pediatric dentistry at the College of Dental Sciences, Bharatpur, Nepal was informed and the infant was examined and advised a feeding appliance on the second day. Patient was in neonatal intensive care unit when the impression making was done. An informed consent was taken before starting the procedure.

It was planned to make the maxillary impression when the infant was fully awake, without any premedication or anesthesia. Because of the small 


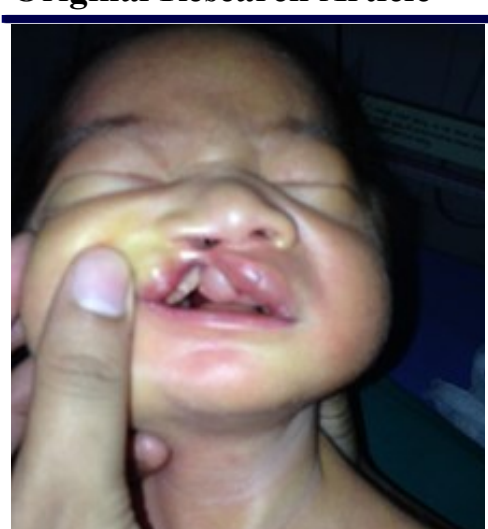

Fig. 1: Extraoral view cleft lip and palate

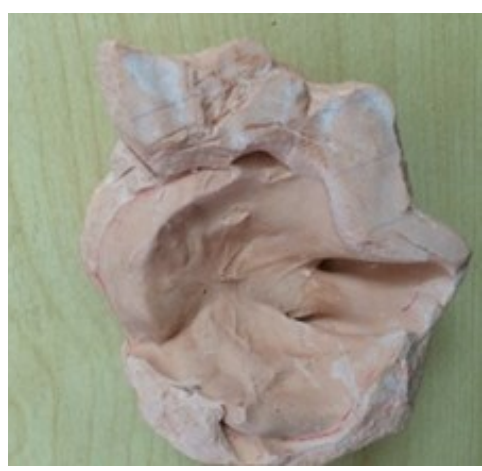

Fig. 4: Master cast

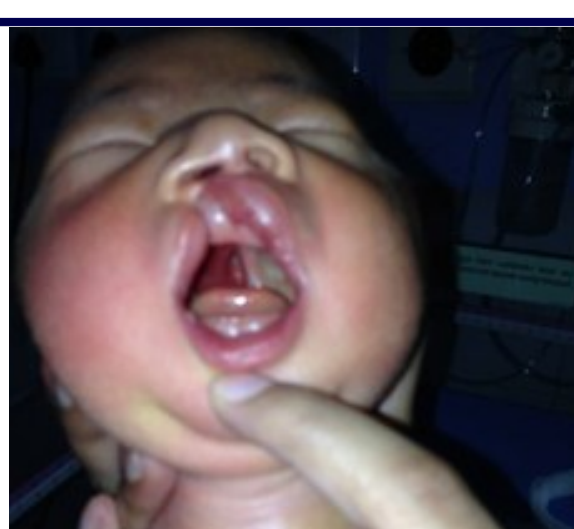

Fig. 2: Extraoral view

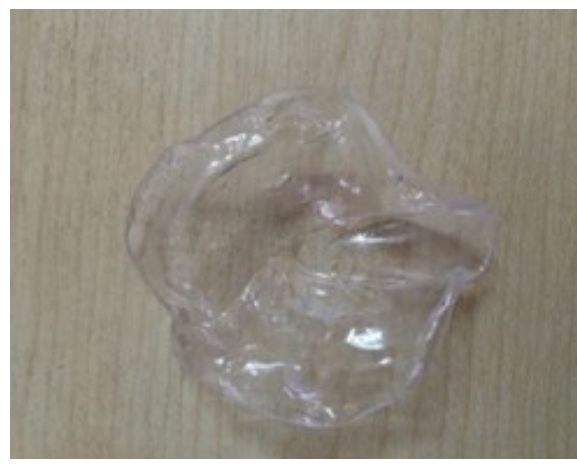

Fig. 5: Feeding appliance

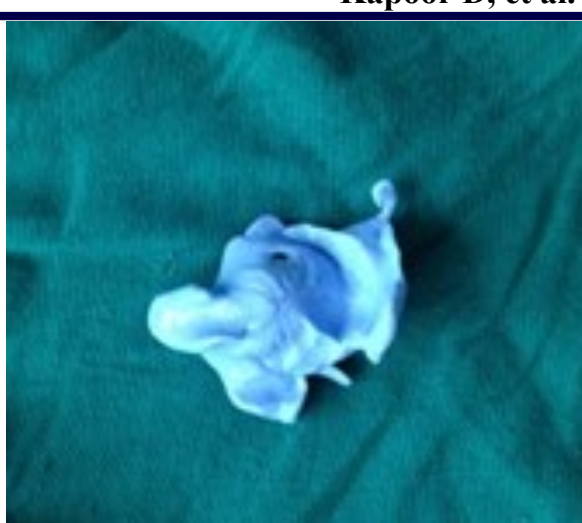

Fig. 3: Putty impression

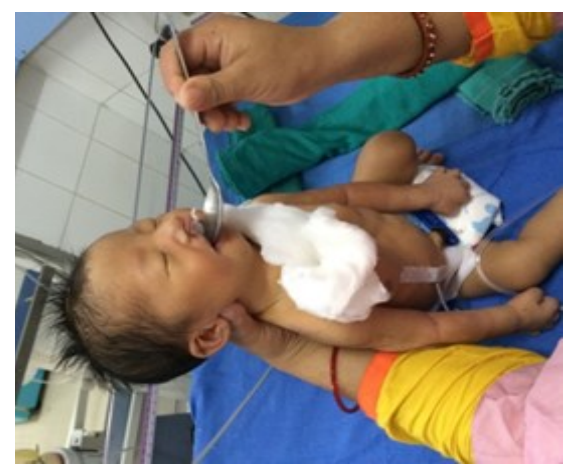

Fig. 6: Patient fed with the feeding appliance oral cavity a finger loaded fast set putty elastomeric impression material was planned. Infant was held in upright position by the NICU staff so that aspiration of the material is prevented. The impression was removed in toto from the patient's mouth after the impression material was set. [Figure 3]Then, the impression was poured and the master cast was obtained. [Figure 4]A feeding obturator was fabricated using clear, flexible thermal $\square$ forming material with a extension for a hole to tie a safety Floss. Finishing and polishing was done to obtain smooth edges. [Figure 5]

There was no nasal regurgitation when the mother fed the neonate using the appliance. The mother could feed the child immediately after insertion without nasal regurgitation. Parents were demonstrated about the use and hygiene maintenance of the feeding plate. [Figure 6] A regular follow up after $24 \mathrm{~h}$ and monthly follow ups later were scheduled and the parents were advised to use the appliance till surgical intervention.

\section{DISCUSSION}

Orofacial clefts pose various problems to the infant including the problem with the feeding and to the development of dentition and speech in the later life. ${ }^{7}$ The overall treatment of such patients is a multidisciplinary approach in which pediatric dentist has a very major role. ${ }^{6}$ Feeding is the foremost concern for such patients and so feeding obturator is given as soon as possible to the patient to ensure the good health as these patients get there surgical treatment started at the age of three to six months. ${ }^{8}$

A soft palate defect has to be obturated well so that the negative pressure required for suckling is obtained and the patient is able to breastfeed. ${ }^{3}$

Various impression materials used are alginate, beeswax, periphery wax, citricon, impression compound and elastomeric putty material. Fast setting putty material is better as it has less chances of aspiration because of its property of high viscosity. ${ }^{1}$ follow up should be done after 24 hours to ensure there are no areas of irritation or ulceration and a new feeding obturator is given approximately after three months simulating the facial growth of the infant.

\section{CONCLUSION}

The treatment of the cases with cleft lip and palate 
is a multidisciplinary approach and the first step is to make the patient comfortably fed so that he gains weight for the surgical procedures to be carried out properly. So, the making of feeding appliance for children born with cleft lip and palate is indispensible. Follow up should be done after 24 hours to ensure there are no areas of irritation or ulceration and a new feeding obturator is given approximately after 3 months simulating the facial growth of the infant.

CONFLICT OF INTEREST: None declared

\section{REFERENCES}

1. Savion I, Huband ML. A feeding obturator for a preterm baby with Pierre Robin sequence. J Prosthet Dent. 2005;93:197-200. https://doi.org/10.1016/ j.prosdent.2004.10.016. PMID: 15674233.

2. Agbenorku P. Orofacial Clefts: A Worldwide Review of the Problem. ISRN Plastic Surgery. 2013:1-7.

3. Karayazgan B, Gunay Y, Gurbuzer B, Erkan M, Atay A. A Preoperative Appliance for a Newborn With Cleft Palate. Cleft Palate-Craniofacial Journal. 2009;46(1):53-57. https://doi.org/10.1597/07-0931. PMID: 19115789.

4. Osuji OO. Preparation of feeding Obturator for infants with cleft lip and palate. J Clin Pediatric Dent. 1995;19:211-4.

5. Choi BH, Kleinbeririz J, Joos U, Komposch G. Sucking efficiency of early orthopedic plate and teats in infants with cleft lip and palate. Int J Oral Maxillofac Surg. 1991;20:167-9. https://doi.org/10.1016/S0901-5027(05) 80009-8

6. Malik P, Aggarwal A, Ahuja R. Feeding appliance for an infant with cleft lip and palate. Pakistan Oral \& Dental Journal. 2012;32(2):264-66.

7. Masih S, Chacko RA, Thomas AM, Singh N, Thomas R, Abrahamet D. Simplified feeding appliance for an infant with cleft palate. JISPPD. 2014;32(4):338-41. https:// doi.org/10.4103/0970-4388.140970

8. Rathee M. Single Visit Feeding Appliance for $1 \square$ day $\square$ old Neonate with Cleft Palate Using Safe Dental Putty $\square$ Gauze Hybrid Impression Technique for Maxillary Impression. Journal of Surgical Technique and Case Report. 2015;7 (1):8-11. https://doi.org/10.4103/2006-8808.184938. PMID: 27512543. 